\title{
DESEMPENHO FÍSICO-QUÍMICO DE METAIS E ESTRUTURAS DE CONCRETO DE REDES DE DISTRIBUIÇÃO DE ENERGIA: ESTUDO DE CASO NA REGIÃO DE MANAUS
}

\author{
Kleber Franke Portella*, Carlos Mario Garcia, Giseli Ribeiro Vergés, Alex Joukoski e Karla Regina Rattmann Freire \\ Instituto de Tecnologia para o Desenvolvimento, CP 19067, 81531-980 Curitiba - PR, Brasil \\ Alcyr de Pinho Corrêa \\ Manaus Energia S.A., Avenida J, 363, 69042-210 Manaus - AM, Brasil \\ Recebido em 14/6/05; aceito em 13/10/05; publicado na web em 18/4/06
}

\begin{abstract}
PHYSICOCHEMICAL PERFORMANCE OF METALS AND CONCRETE STRUCTURES USED IN ELECTRICITY DISTRIBUTION NETWORKS: CASE STUDY IN MANAUS REGION. The influence of natural aging furthered by atmospheric corrosion of parts of electric transformers and materials, as well as of concrete poles and cross arms containing corrosion inhibitors was evaluated in Manaus. Results for painted materials, it could showed that loss of specular gloss was more intensive in aliphatic polyurethane points than in acrylic polyurethane ones. No corrosion was observed for metal and concrete samples until 400 days of natural aging. Corrosion in steel reinforcement was noticed in some poles, arising from manufacturing faults, such as low cement content, water/cement ratio, thin concrete cover thickness, etc. The performance of corrosion inhibitors was assessed by many techniques after natural and accelerated aging in a $3.5 \%$ saline aqueous solution. The results show the need for better chemical component selection and its concentration in the concrete mixture.
\end{abstract}

Keywords: paints; reinforced concrete; materials for electric energy distribution networks.

\section{INTRODUÇÃO}

As perdas financeiras ocasionadas pelos processos de degradação e corrosão das estruturas metálicas e de concreto são, em geral, muito elevadas. Nos Estados Unidos o custo anual da corrosão chega a $3,1 \%$ do PIB, o que totaliza US\$ 276 bilhões, contra 3,5\% no Brasil ${ }^{1}$. Isto tem motivado amplo desenvolvimento da pesquisa neste campo da Engenharia.

Os custos indiretos devidos a efeitos derivados, tais como interrupção no funcionamento de estabelecimentos industriais, contaminação de produtos, danos a equipamentos próximos daquele no qual ocorreu a falha, problemas de segurança (incêndios, explosões, liberação de produtos tóxicos, colapso das construções), acidentes pessoais com perda de vida, etc. aumentam exponencialmente a conta final.

A corrosão pode ser definida como o ataque não-intencional que ocorre em um material por causa da reação deste com determinados componentes químicos contidos no meio em que está inserido. Assim, por ex., uma análise química da água das chuvas nos grandes centros urbanos, tal como São Paulo ${ }^{2}$, revela a presença de íons agressivos que vem aumentando, consideravelmente, com o passar dos anos e sua influência nos materiais de engenharia ainda é pouco conhecida. São susceptíveis de degradar (corroer) materiais tão diferentes como metais, madeiras, cerâmicas, polímeros, entre outros. No entanto, as causas que originam a deterioração são diferentes, dependendo do material de partida. Todos estes processos são de natureza espontânea, ou seja, fixado o material e o meio ambiente, este ocorrerá, com maior ou menor velocidade e maior ou menor intensidade.

O objetivo é propor meios viáveis e de baixo custo para aumento da vida útil dos produtos finais.

Para a proteção dos metais é tradicional o uso de tintas orgânicas, recobrimentos metálicos e não-metálicos, tais como as camadas galvanizadas, fosfatizadas, aluminizadas, anodizadas, etc. São, normalmente, eficazes contra o processo corrosivo, mas de-

*e-mail: portella@lactec.org.br pendem de vários fatores: método de aplicação, meio ambiente, tempo de exposição à intempérie, entre outros. Um menor desempenho contra a corrosão do substrato protegido é quase sempre verificado em regiões de alta agressividade ambiental, em atmosferas marítimas e industriais. Nestas regiões, a vida útil de materiais metálicos como o aço carbono usado em transformadores de redes de distribuição de energia elétrica (RDE's) é extremamente reduzida, constatando-se casos de furos no tanque de óleo devido à corrosão, em tempo de operação médio de um ano $^{3}$, o que estimula a um estudo mais aprofundado do mecanismo de degradação envolvido.

Nestes casos, o problema poderá não estar centrado no recobrimento ou pintura bem sucedidos, com demãos de fundo, intermediária e acabamento, mas sim, na escolha inadequada do componente químico de proteção da tinta (resina e pigmentos), da qualidade superficial do metal de base e da metodologia de aplicação. Assim, tem-se maior ou menor resistência à radiação solar, à umidade e aos agentes agressivos externos (gás carbônico, chuva ácida, cloretos, radiação UV, etc.). A exposição de transformadores de RDE's em regiões da orla marítima do Estado do Paraná, pintados com sistemas de pintura e técnicas adequados, tem demonstrado vida útil maior (superior a 10 anos), em virtude do conhecimento das condições atmosféricas locais quanto à sua agressividade química ${ }^{4}$.

Diversas técnicas analíticas vêm sendo empregadas com objetivo de melhor caracterizar o desempenho das tintas ao longo da sua exposição ao meio ambiente. Dentre estas, destaca-se a medida do brilho, característica que depende essencialmente da quantidade de pigmentos no seu volume, sendo brilhante quando em pouca concentração - uma vez que estes tendem a ficar submersos na resina e fosca ou sem brilho, no caso oposto, onde parte deste material acaba ficando exposta à superfície ${ }^{5}$, como se observa, esquematicamente, na Figura 1. A vantagem na sua medida é a possibilidade de acompanhar a degradação da tinta em função do tempo de exposição, pelos efeitos da radiação solar, oxigênio e chuvas ${ }^{5}$, como 
observado, esquematicamente, na Figura 2. A degradação da resina acaba por deixar expostas as partículas de pigmento, diminuindo seu brilho com o tempo. A análise tem como resultado valores em unidades de brilho (UB). Esta unidade pode ser compreendida fazendo-se analogia a um espelho perfeito, uma vez que este reflete $100 \%$ da luz incidente. Assim, uma tinta considerada muito brilhante e com cerca de 98 UB teria, comparativamente, 9,8\% do brilho de um espelho perfeito.


Figura 1. Esquemas de uma tinta brilhante e de uma tinta fosca, quando submetidas a uma radiação incidente. Reproduzido da ref. 5, com permissão da Sherwin Williams do Brasil

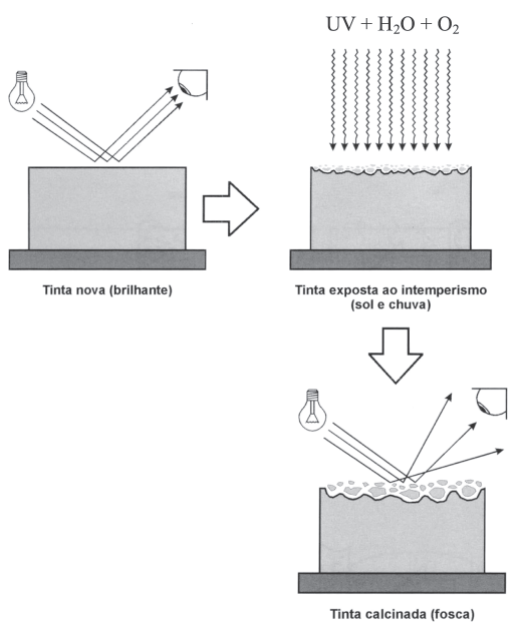

Figura 2. Efeito esquemático da radiação solar, chuva e oxigênio sobre os revestimentos orgânicos (tintas). Reproduzido da ref. 5, com permissão da Sherwin Williams do Brasil

No caso das estruturas em concreto armado, em que suas excelentes propriedades são resultantes da elevada resistência à compressão do concreto associada à forte resistência à tração do aço, o recobrimento da armadura constitui não somente uma barreira física que separa o aço do meio externo mas, também, o fornecimento de um meio alcalino ideal no qual o aço estará protegido contra corrosão. Neste último caso, pode-se considerar que o concreto armado é um par quase perfeito, com estimativa de vida útil bastante prolongada.

No caso de postes e cruzetas de uma RDE, a durabilidade também é conseqüente da qualidade dos insumos (cimento, agregados, água e aditivos); das variáveis relativas ao controle de qualidade na fabricação, tais como relação dos materiais envolvidos; da quanti- dade de cimento por volume; da relação água/cimento $(\mathrm{a} / \mathrm{c})$; do desmoldante utilizado; do método e tempo de desmoldagem e cura; da espessura de recobrimento da armadura; do armazenamento e transporte e da sua aplicação, pois, dependendo do meio ambiente e da carga solicitada, um novo tipo ou mistura de agente aglomerante terá que ser considerado ${ }^{6-9}$. Na prática, observa-se que a menor durabilidade destas estruturas está quase sempre atrelada a uma baixa qualidade dos insumos e no processo de fabricação. É comum a fabricação de estruturas de concreto armado com consumo de cimento menor que o mínimo recomendado na literatura ${ }^{7}$ e em nor$\mathrm{ma}^{8}$, ou mesmo, com a relação a/c sem controle rígido ou ao sentimento do operador da betoneira e, também, o descaso em não manter, durante um período mínimo de tempo, a cura úmida do concreto após o enchimento das fôrmas.

Estes itens apontados são, na maioria dos casos, os responsáveis pelas baixas durabilidade e qualidade dos produtos de engenharia das RDE's, escopo deste trabalho.

\section{PARTE EXPERIMENTAL}

O trabalho foi realizado em três etapas. Na primeira, ocorreu a caracterização e o levantamento na RDE da cidade de Manaus dos materiais de engenharia com indícios visuais de corrosão ou degradação. Também, nesta etapa, foi escolhido um local de maior representatividade para instalação de uma estação de corrosão atmosférica (ECA), para exposição e ensaios em campo dos materiais e aquisição de dados relativos às condições climáticas, segundo a sazonalidade. Na segunda etapa procurou-se caracterizar todos os insumos trabalhados a partir de métodos físico-químicos. Na terceira, empreenderam-se a fabricação dos corpos-de-prova (CP's), sua exposição na ECA de Manaus e posterior caracterização ao longo do envelhecimento natural e artificial, utilizando-se a metodologia descrita na seqüência.

\section{Inspeção visual}

Técnica escolhida em razão da pouca necessidade de instrumentos de medida e por oferecer um poder de investigação mais acurado. É, na maioria dos casos, eficaz na constatação de processos de degradação e do envelhecimento dos materiais. Porém, por não ser uma técnica conclusiva na determinação da causa da degradação, é necessária a retirada de CP's e amostras de materiais para análise por outras técnicas analíticas em laboratório.

\section{Escolha e implantação da ECA}

A ECA foi construída em local representativo da região de Manaus e segundo as normas NBR $6209^{10}$ e NBR $7011^{11}$. Os painéis de exposição foram fabricados de acordo com estas normas e o período compreendeu cerca de 13 meses de exposição ao intemperismo natural da cidade de Manaus. Os parâmetros atmosféricos analisados foram umidade relativa (UR), índice pluviométrico, taxa de insolação, direção e velocidade dos ventos e temperatura local ${ }^{12}$.

Os estudos de envelhecimento natural e acelerado foram idealizados com os materiais de base da RDE, compreendendo os revestimentos orgânicos e inorgânicos e chapas laminadas, com dimensões de 200 x 100 mm, dos seguintes materiais: aço carbono 1010; aço galvanizado com revestimento de zinco puro (espessura média de $24 \pm 4,0$ $\mu \mathrm{m}$ ); aço com revestimento "galvalume" (liga de zinco e alumínio, com espessura média de $34 \pm 3,5 \mu \mathrm{m}$; e alumínio $(99,9 \%$ de pureza) ${ }^{13}$. O preparo da superfície foi realizado de acordo com as recomendações do fabricante das tintas, assim como a pintura dos mesmos, conforme listados na Tabela 1 . 
Tabela 1. Sistemas substrato-pintura propostos para estudos de desempenho sob envelhecimento acelerado em névoa salina e na ECA de Manaus.

\begin{tabular}{|c|c|c|c|}
\hline Sistema $^{a}$ & Fundo & Intermediário & Acabamento \\
\hline 1: CZAC & $\begin{array}{l}\text { Epóxi rico em zinco; } \\
\text { Espessura: } 80 \mu \mathrm{m} ; \\
\text { Diluente: } 20 \%\end{array}$ & $\begin{array}{l}\text { Epóximastic de } \mathrm{Al} ; 1 \text { demão diluição } \\
40 \% ; 1 \text { demão diluição } 20 \% \text {; } \\
\text { Espessura: } 80-100 \mu \mathrm{m}\end{array}$ & $\begin{array}{l}\text { Poliuretano acrílico; } \\
\text { Espessura: } 60 \mu \mathrm{m} ; \\
\text { Diluente: } 20 \%\end{array}$ \\
\hline 2: CZAL & $\begin{array}{l}\text { Epóxi rico em zinco; } \\
\text { Espessura: } 80 \mu \mathrm{m} ; \\
\text { Diluente: } 20 \%\end{array}$ & $\begin{array}{l}\text { Epóximastic de } \mathrm{Al} ; 1 \text { demão diluição } \\
\text { 40\%; } 1 \text { demão diluição } 20 \% \text {; } \\
\text { Espessura: } 80-100 \mu \mathrm{m}\end{array}$ & $\begin{array}{c}\text { Poliuretano alifático; } \\
\text { Espessura: } 30 \mu \mathrm{m} ; \\
\text { Diluente: } 20 \%\end{array}$ \\
\hline 3: CZAQ & $\begin{array}{l}\text { Epóxi rico em zinco; } \\
\text { Espessura: } 80 \mu \mathrm{m} ; \\
\text { Diluente: } 20 \%\end{array}$ & $\begin{array}{l}\text { Epóximastic de } \mathrm{Al} ; 1 \text { demão diluição } \\
40 \% ; 1 \text { demão diluição } 20 \% \text {; } \\
\text { Espessura: } 80-100 \mu \mathrm{m}\end{array}$ & $\begin{array}{l}\text { Alquídico; } \\
\text { Espessura: } 30 \mu \mathrm{m} \text {; } \\
\text { Diluente: } 10 \%\end{array}$ \\
\hline 4: CFAC & $\begin{array}{l}\text { Epóxi óxido de ferro; } \\
\text { Espessura: } 120 \mu \mathrm{m} ; \\
\text { Diluente: } 20 \%\end{array}$ & $\begin{array}{c}\text { Epóximastic de Al; } 2 \text { demãos; } \\
\text { Espessura: } 80-100 \mu \mathrm{m} \text {; Diluente: } 20 \%\end{array}$ & $\begin{array}{l}\text { Poliuretano acrílico; } \\
\text { Espessura: } 60 \mu \mathrm{m} ; \\
\text { Diluente: } 20 \%\end{array}$ \\
\hline 5: CFAL & $\begin{array}{l}\text { Epóxi óxido de ferro; } \\
\text { Espessura: } 120 \mu \mathrm{m} ; \\
\text { Diluente: } 20 \%\end{array}$ & $\begin{array}{l}\text { Epóximastic de Al; } 2 \text { demãos; } \\
\text { Espessura: } 80-100 \mu \mathrm{m} \text {; Diluente: } 20 \%\end{array}$ & $\begin{array}{l}\text { Poliuretano alifático; } \\
\text { Espessura: } 30 \mu \mathrm{m} ; \\
\text { Diluente: } 20 \%\end{array}$ \\
\hline 6: CFAQ & $\begin{array}{l}\text { Epóxi óxido de ferro; } \\
\text { Espessura: } 120 \mu \mathrm{m} ; \\
\text { Diluente: } 20 \%\end{array}$ & $\begin{array}{c}\text { Epóximastic de Al; } 2 \text { demãos; } \\
\text { Espessura: } 80-100 \mu \mathrm{m} \text {; Diluente: } 20 \%\end{array}$ & $\begin{array}{l}\text { Alquídico; } \\
\text { Espessura: } 30 \mu \mathrm{m} \text {; } \\
\text { Diluente: } 10 \%\end{array}$ \\
\hline 7: CMAC & $\begin{array}{l}\text { EpAlOxFe; } \\
\text { Espessura: } 125 \mu \mathrm{m} \\
\text { Diluente: } 15 \%\end{array}$ & $\begin{array}{c}\text { Epóximastic de Al; } 2 \text { demãos; } \\
\text { Espessura: } 80-100 \mu \mathrm{m} \text {; Diluente: } 20 \%\end{array}$ & $\begin{array}{l}\text { Poliuretano acrílico; } \\
\text { Espessura: } 60 \mu \mathrm{m} ; \\
\text { Diluente: } 20 \%\end{array}$ \\
\hline 8: CMAL & $\begin{array}{l}\text { EpAlOxFe; } \\
\text { Espessura: } 125 \mu \mathrm{m} \text {; } \\
\text { Diluente: } 15 \%\end{array}$ & $\begin{array}{c}\text { Epóximastic de Al; } 2 \text { demãos; } \\
\text { Espessura: } 80-100 \mu \mathrm{m} \text {; Diluente: } 20 \%\end{array}$ & $\begin{array}{c}\text { Poliuretano alifático; } \\
\text { Espessura: } 30 \mu \mathrm{m} ; \\
\text { Diluente: } 20 \%\end{array}$ \\
\hline 9: CMAQ & $\begin{array}{l}\text { EpAlOxFe; } \\
\text { Espessura: } 125 \mu \mathrm{m} \text {; } \\
\text { Diluente: } 15 \%\end{array}$ & $\begin{array}{c}\text { Epóximastic de Al; } 2 \text { demãos; } \\
\text { Espessura: } 80-100 \mu \mathrm{m} \text {; Diluente: } 20 \%\end{array}$ & $\begin{array}{c}\text { Alquídico; } \\
\text { Espessura: } 30 \mu \mathrm{m} \text {; } \\
\text { Diluente: } 10 \%\end{array}$ \\
\hline $\begin{array}{l}\text { 10: ZBAC } \\
\text { 11: GBAC } \\
\text { 12: ABAC }\end{array}$ & $\begin{array}{l}\text { Polivinilbutiral } \\
\text { Espessura: } 8-12 \mu \mathrm{m}\end{array}$ & $\begin{array}{c}\text { Epóximastic de Al; } 2 \text { demãos; } \\
\text { Espessura: } 100 \mu \mathrm{m} \text {; Diluente: } 20 \%\end{array}$ & $\begin{array}{c}\text { Poliuretano acrílico; } \\
\text { Espessura: } 60 \mu \mathrm{m} \text {; } \\
\text { Diluente: } 20 \%\end{array}$ \\
\hline $\begin{array}{l}\text { 13: ZBAL } \\
\text { 14: GBAL } \\
\text { 15: ABAL }\end{array}$ & $\begin{array}{l}\text { Polivinilbutiral } \\
\text { Espessura: } 8-12 \mu \mathrm{m}\end{array}$ & $\begin{array}{c}\text { Epóximastic de Al; } 2 \text { demãos; } \\
\text { Espessura: } 100 \mu \mathrm{m} \text {; Diluente: } 20 \%\end{array}$ & $\begin{array}{c}\text { Poliuretano alifático; } \\
\text { Espessura: } 30 \mu \mathrm{m} ; \\
\text { Diluente: } 20 \%\end{array}$ \\
\hline $\begin{array}{l}\text { 16: ZBAQ } \\
\text { 17: GBAQ } \\
\text { 18: ABAQ }\end{array}$ & $\begin{array}{l}\text { Polivinilbutiral } \\
\text { Espessura: } 8-12 \mu \mathrm{m}\end{array}$ & $\begin{array}{c}\text { Epóximastic de } \mathrm{Al} ; 2 \text { demãos; } \\
\text { Espessura: } 100 \mu \mathrm{m} \text {; Diluente: } 20 \%\end{array}$ & $\begin{array}{c}\text { Alquídico; } \\
\text { Espessura: } 30 \mu \mathrm{m} \text {; } \\
\text { Diluente: } 10 \%\end{array}$ \\
\hline
\end{tabular}

${ }^{\mathrm{a} A}$ primeira letra refere-se ao metal de base, sendo: C - aço carbono 1010; Z - galvanizado; G - galvalume; A - alumínio. ${ }^{\mathrm{b}}$ EpAlOxFe: Epóxi alumínio óxido de ferro.

A metodologia de trabalho seguiu com estudos de laboratório nos CP's devidamente preparados e identificados, iniciando-se pela análise dos esquemas de pintura antes, durante e após os períodos de envelhecimento natural e artificial. $\mathrm{O}$ envelhecimento natural foi realizado por meio da exposição das amostras na ECA de Manaus, enquanto que para o artificial foram utilizadas câmaras de intemperismo de névoa salina.

\section{Resistência à névoa salina}

O procedimento seguiu a norma ASTM B117 14 , e as amostras foram expostas à salinidade em uma câmara de névoa salina BASS, com solução de cloreto de sódio $(\mathrm{NaCl})$ em água deionizada a $5 \%$ (50 g/L). O pH da solução ficou entre 6,5 e 7,2, o fluxo de névoa salina, médio, entre ( 1 e 2 ) $\mathrm{mL} / \mathrm{h}$ e a temperatura de trabalho de 35 $\pm 2{ }^{\circ} \mathrm{C}$. Foram expostos, também, CP's de cada sistema de pintura, contendo incisão central (corte) até o substrato, por 3500 h nas condições descritas.

\section{Avaliação da resistência ao intemperismo natural e acelerado em névoa salina neutra e contínua até $3500 \mathrm{~h}$}

A análise dos materiais envelhecidos em atmosfera natural e sob névoa salina artificial foi executada, periodicamente, durante a exposição e incluiu a avaliação dos seguintes parâmetros: inspeção visual e documentação fotográfica; alastramento da corrosão; medida de espessura do $\mathrm{CP}$; cor $^{15}$; brilho $^{5}$; grau de empolamento ${ }^{16}$; grau de enferrujamento ${ }^{17}$; gizamento ${ }^{18}$; descamação ${ }^{19}$; aderência $^{20}$; gretamento $^{21}$ e fendilhamento ${ }^{22}$.

Os estudos dos mecanismos de degradação foram efetuados por interpretação dos resultados analíticos realizados antes, durante e após o envelhecimento. 


\section{Artefatos de concreto}

Foram estudados e desenvolvidos, em laboratório, traços de concreto com cimentos, agregados e consumo similares aos utilizados pelos fabricantes de postes, cruzetas e contrapostes locais e, também, traços com adição de substâncias químicas inibidoras de corrosão da armadura, para estudo de desempenho frente ao ambiente urbano de Manaus e em ambiente artificial, com dados físico-químicos controlados, tais como temperatura, umidade e solução salina a $3,4 \%$ de $\mathrm{NaCl}$.

No laboratório, deu-se ênfase ao estudo das propriedades elétricas dos CP's de concreto armado, por intermédio das técnicas de espectroscopia de impedância eletroquímica ${ }^{12}$, potencial de corrosão e resistência elétrica, com espessuras de cobrimento idênticas ao do estudo de campo em andamento. As propriedades dos materiais, medidas nos CP's, foram correlacionadas aos envelhecimentos natural e acelerado (em câmaras de intemperismo artificial). As principais técnicas utilizadas encontram-se listadas na seqüência.

\section{Absorção de água e propriedades físicas}

A determinação do teor de absorção de água, massa específica e índice de vazios, dos concretos, foi realizada de acordo com os métodos descritos na norma técnica NBR $9778^{23}$.

\section{Microscopia eletrônica de varredura (MEV) e microanálise por microssonda analítica de raios $\mathrm{X}$ (EDS)}

As análises da micrografia e da composição química foram verificadas nas superfícies polidas e de fratura dos materiais. Para esta técnica foi utilizado equipamento Philips, modelo XL 30, equipado com detector de raios X para microanálise, marca EDAX.

\section{Espectrofotometria de absorção atômica (AA) e cromatografia iônica (CI)}

Foram as técnicas utilizadas para determinação da composição química dos insumos do concreto. Usaram-se um equipamento Perkin-Elmer, modelo 4110, e um cromatógrafo de íons Dionex, modelo 2010 I.

\section{Difração de raios X (DRX)}

Com o objetivo de identificar as fases cristalinas presentes nos materiais, foi utilizado equipamento Philips, modelo X'Pert MPD, com radiação $\mathrm{Cu}-\mathrm{K} \alpha$ de comprimento de onda $\lambda$ de 1,54051 $\mathrm{A}$, varredura em $2 \theta$ entre $10^{\circ}$ e $90^{\circ}$, tensão de $40 \mathrm{kV}$, corrente de $40 \mathrm{~mA}$, passo de 0,001 e velocidade de passo igual a $0,002 \mathrm{p} / \mathrm{s}$. Os picos de difração foram identificados por intermédio do banco de dados do "International Centre for Diffraction Data (ICDD)" e software do equipamento.

\section{Propriedades eletroquímicas}

Para verificar a degradação do concreto e a corrosão da armadura metálica foram usadas a técnica de espectroscopia de impedância eletroquímica (EIS) ${ }^{12}$ e as medidas do potencial de corrosão de CP's expostos a ambientes naturais e artificiais pelo período de 1 ano. A importância de tais técnicas vem de sua sensibilidade a quaisquer alterações eletroquímicas ocorridas no "bulk" do material analisado e, também, por serem não-destrutivas, podendo o material continuar exposto ao ambiente para futuras avaliações. Para as medidas eletroquímicas utilizou-se equipamento marca Eco-Chemie, mode- lo Autolab 20, monitorado por microcomputador, em varredura descendente de freqüência entre $50 \mathrm{kHz}$ e $10 \mathrm{mHz}$, com eletrodo de referência de calomelano saturado.

Os CP's para ensaios, com e sem inibidores de corrosão, foram conformados em molde de aço inoxidável, conforme mostrado na Figura 3 , e de forma a simular estruturas reais de concreto armado. Cada molde tem capacidade para confecção de 6 CP's, no formato de prismas de dimensões iguais a $100 \mathrm{~mm}$ (altura), $91 \mathrm{~mm}$ (largura) e $49 \mathrm{~mm}$ (espessura); suas moldagem e cura foram baseadas nas orientações da norma NBR $5738^{24}$. O molde consistiu de um sistema de encaixes para barras de aço (vergalhões), classe CA 50, nervuradas. O diâmetro nominal previsto foi de $6,3 \mathrm{~mm}$, sendo representativo da armadura em estruturas de concreto armado. Também, o sistema tem a vantagem de funcionar como eletrodos metálicos capazes de auxiliar nas medidas eletroquímicas. Ambas as extremidades das barras foram chanfradas com auxílio de esmeril, para eliminar qualquer "efeito de ponta" (início preferencial de atividade corrosiva em regiões com cantos vivos). Em seguida, foi efetuado jateamento com granalha de aço em câmara especial, para eliminar a camada formada de óxido superficial e obter aspecto metálico brilhante.


Figura 3. Fotografias da fôrma de aço inoxidável, contendo barras metálicas, para confecção de CP's de concreto para medidas eletroquímicas

Para utilização das barras nos CP's fez-se necessário delimitar a área de estudo para facilitar o monitoramento do processo de corrosão, pintando-se suas extremidades com tinta anti-corrosiva à base de epóxi com alcatrão de hulha, a fim de se obter apenas um trecho central exposto nas mesmas, com área geométrica média de $6,4 \mathrm{~cm}^{2}$. O motivo desta pintura foi, também, proteger a superfície metálica contra a ação corrosiva em duas zonas distintas: no trecho localizado na região da interface entre o concreto e o ambiente e na extremidade que fica inserida no CP. A foto e o desenho esquemático, apresentados na Figura 4, ilustram o aspecto dos CP's obtidos.

\section{Dosagens do concreto $^{24-29}$}

As dosagens foram feitas usando-se como padrão o traço médio de referência obtido nas fábricas de postes, cruzetas e contrapostes instalados na RDE da região de Manaus e a confecção dos concretos foi realizada de acordo com a norma NBR $5738^{24}$, sendo estabelecida 


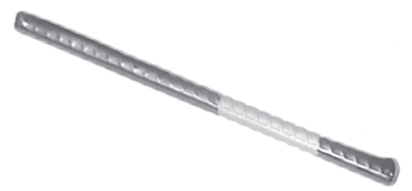

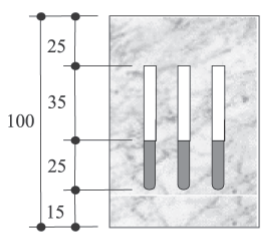

unidades em mm

VISTA FRONTAL (em corte)

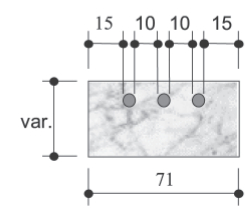

VISTA SUPERIOR

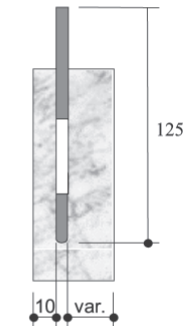

VISTA LATERAL (em corte)
Figura 4. Vergalhão CA 50, pintado nas extremidades, utilizado como eletrodo de medida eletroquímica e desenhos esquemáticos da disposição das barras no interior dos CP's, vistas de frente, lado e superior, respectivamente uma relação a/c máxima de $0,52 \pm 0,01$. Os materiais utilizados e o traço encontram-se listados nas Tabelas 2,3 e 4.

Alguns CP's de concreto foram dosados com agregados graúdos tipo brita 1 e não com seixo da região e com inibidores de corrosão disponíveis comercialmente, na proporção e forma indicadas pelo fabricante, conforme listagem da Tabela 3. O emprego da pedra brita deveu-se à sua maior taxa de utilização nacional, dentre outras pesquisas realizadas ${ }^{10,27}$.

Todos os materiais foram submetidos a análises físico-químicas e mecânicas, de acordo com as normas brasileiras correspondentes. A proporcionalidade dos insumos constituintes do concreto foi realizada em planilha de cálculo de dosagem experimental.

\section{Moldagem dos CP's de concreto}

Os traços de concreto com inibidores de corrosão foram misturados em betoneira por um período de, aproximadamente, $8 \mathrm{~min}$. Sua trabalhabilidade foi avaliada pela consistência no abatimento do tronco de cone ("slump"), conforme recomendações da NBR $7223^{25}$.

Após o preenchimento com concreto e seu adensamento em mesa vibratória, o conjunto de moldes prismáticos foi totalmente envolto em filme de PVC transparente, com a finalidade de evitar a perda da água do concreto, o qual foi mantido no ambiente do laboratório por $24 \mathrm{~h}$. A desmoldagem foi feita após $48 \mathrm{~h}$, e os CP's foram mantidos sob cura em câmara úmida por um período total de 28 dias. Após, as amostras foram codificadas e destinadas para exposição natural em campo e envelhecimento acelerado em laboratório.

Os CP's de laboratório, após o período de cura, foram submetidos a dois tipos de testes: imersão parcial contínua em solução aquosa de cloreto de sódio a 3,5\% (neste caso, somente, a metade do CP fi-

Tabela 2. Materiais utilizados para confecção dos CP's de concreto com e sem aditivos inibidores de corrosão

\begin{tabular}{|c|c|c|c|c|c|c|c|c|}
\hline Dosagem & Branco $^{a}$ & 1 & 2 & 3 & 4 & 5 & 6 & 7 \\
\hline \multicolumn{9}{|l|}{ Traço em peso } \\
\hline Cimento CPII-Z 32 & \multicolumn{8}{|c|}{1} \\
\hline Areia & \multicolumn{8}{|c|}{2,02} \\
\hline Pedrisco & \multicolumn{8}{|c|}{0,89} \\
\hline Brita 1 & \multicolumn{8}{|c|}{2,09} \\
\hline $\mathrm{a} / \mathrm{c}^{\mathrm{b}}$ & 0,524 & 0,509 & 0,524 & 0,517 & 0,517 & 0,524 & 0,525 & 0,524 \\
\hline \multicolumn{9}{|c|}{ Consumos $\left(\mathrm{kg} / \mathrm{m}^{3}\right)$} \\
\hline Cimento CPII-Z 32 & 366 & 363 & 359 & 362 & 366 & 363 & 365 & 362 \\
\hline Areia & 740 & 734 & 726 & 732 & 740 & 734 & 738 & 732 \\
\hline Pedrisco & 326 & 324 & 320 & 323 & 326 & 324 & 325 & 323 \\
\hline Brita 1 & 765 & 759 & 751 & 757 & 765 & 759 & 763 & 757 \\
\hline Água & 192 & 185 & 189 & 188 & 190 & 191 & 192 & 190 \\
\hline Aditivo $^{c}$ & - & 15 & 25 & 5 & 31 & 32 & 33 & 5 \\
\hline Teor agregado miúdo $(\%)$ & \multicolumn{8}{|c|}{40,4} \\
\hline Relação 1:m & \multicolumn{8}{|c|}{$1: 5($ ou 0,20$)$} \\
\hline Relação pedrisco/brita (\%) & \multicolumn{8}{|c|}{$30 / 70$} \\
\hline Slump (mm) & 30 & 35 & 35 & 40 & 30 & 30 & 30 & 30 \\
\hline \multicolumn{9}{|c|}{ Massa unitária $\left(\mathrm{kg} / \mathrm{m}^{3}\right)$} \\
\hline Teórica & 2348 & 2356 & 2348 & 2352 & 2352 & 2348 & 2348 & 2348 \\
\hline Real & 2385 & 2358 & 2342 & 2356 & 2383 & 2367 & 2378 & 2361 \\
\hline
\end{tabular}

${ }^{a}$ Branco: corresponde ao concreto-referência, sem utilização de aditivos; ${ }^{b}$ a/c: fator água/cimento; ${ }^{\circ}$ os aditivos químicos (inibidores de corrosão) utilizados encontram-se listados na Tabela 3; ${ }^{\mathrm{d}} 1: \mathrm{m}$ : relação cimento/agregado total. 
cou submersa na solução, sendo a outra metade exposta ao ar, à 22 ${ }^{\circ} \mathrm{C}$ e $60 \%$ de umidade relativa, UR, código utilizado: $I P C$ ) e, a ciclos semanais de 2 dias de imersão total do CP na solução salina, intercalados com 5 dias de exposição ao ar, também, à $22{ }^{\circ} \mathrm{C}$ e $60 \%$ de UR (código para o ciclo de imersão descontínua: $C I D$ ).

\section{Análise petrográfica dos agregados e estudo de reatividade potencial}

Os testes para determinação de possíveis reações expansivas no concreto fabricado com cimento e agregados oriundos da cidade de Manaus foram realizados segundo orientações de normas técnicas e de metodologias apresentadas na literatura ${ }^{27}$.

\section{RESULTADOS E DISCUSSÃO}

\section{Inspeção visual}

Parte dos transformadores da RDE de Manaus, retirados para manutenção, apresentou corrosão vermelha generalizada no tanque de óleo mineral e nas aletas de refrigeração (radiador), conforme pode ser observado na Figura 5 (as manchas escuras sobre a carcaça correspondem à região afetada pela corrosão). Nos casos extremos foi observada, também, perfuração do tanque, com derramamento de óleo do interior do equipamento, conforme detalhe mostrado na própria figura (seta).

Apesar das ocorrências observadas, o tempo médio de aparecimento dos problemas de corrosão foi superior a 15 anos, com pouca incidência em tempos inferiores.

No caso das estruturas de concreto, postes tipo duplo T e circulares, alguns defeitos superficiais foram verificados, como fratura na região do terço superior (cerca de $1 \mathrm{~m}$ abaixo do topo) do poste, conforme exemplificado na Figura 6; corrosão generalizada da armadura, com desplacamento da cobertura de concreto, conforme Figura 7; porosidade superficial elevada, pontos de manchamento por corrosão acentuada da armadura, trincas de retração e, falhas de concretagem, conhecidas no meio técnico como "bicheiras" superficiais à estrutura, tal como Figura 8.

Estes defeitos superficiais foram atribuídos, principalmente, ao processo de fabricação dos artefatos, em consequiência de: baixo consumo de cimento $/ \mathrm{m}^{3}$ de concreto $\left(150 \mathrm{~kg} / \mathrm{m}^{3}\right)$, resultando em estruturas com resistência mecânica baixa; relação a/c não especificada ou ina-

Tabela 3. Relação dos inibidores comerciais utilizados, com sua respectiva dosagem e composição

\begin{tabular}{llcl}
\hline Aditivo & Dosagem recomendada & Dosagem utilizada & Composição \\
\hline 01 & 3 a $4 \%$ em relação ao peso de cimento & $4 \%$ & Compostos orgânicos e inorgânicos \\
02 & 15 a $30 \mathrm{~L} / \mathrm{m}^{3}$ de concreto & $25 \mathrm{~L} / \mathrm{m}^{3}$ & Nitrito de cálcio \\
03 & $5 \mathrm{~L} / \mathrm{m}^{3}$ de concreto & $0,2 \mathrm{~L}$ & Inorgânico - base fosfato \\
04 & $15 \mathrm{a} 30 \mathrm{~L} / \mathrm{m}^{3}$ de concreto & $25 \mathrm{~L} / \mathrm{m}^{3}$ & Inorgânico - base nitrito de cálcio \\
05 & 15 a $30 \mathrm{~L} / \mathrm{m}^{3}$ de concreto & $25 \mathrm{~L} / \mathrm{m}^{3}$ & Inorgânico - base nitrito de cálcio com acelerador de cura \\
06 & 15 a $30 \mathrm{~L} / \mathrm{m}^{3}$ de concreto. & $25 \mathrm{~L} / \mathrm{m}^{3}$ & Inorgânico - base 30\% nitrito de cálcio \\
07 & $5 \mathrm{~L} / \mathrm{m}^{3}$ para qualquer aplicação & $0,2 \mathrm{~L}$ & Compostos orgânicos (éster e amina) \\
Referência & em ambiente corrosivo & $7,6 \mathrm{~L}$ & SSP - Solução sintética de poros \\
\hline
\end{tabular}

Tabela 4. CP's de concreto fabricados com insumos da região de Manaus.

\begin{tabular}{|c|c|c|}
\hline Dosagem & Fabr. Manaus ${ }^{\mathrm{a}}$ & Laboratório $^{\mathrm{b}}$ \\
\hline \multicolumn{3}{|c|}{ Traço em peso } \\
\hline Cimento CPII-F 32 & 1 & \\
\hline$\overline{\text { Areia }}$ & 3,47 & 1,89 \\
\hline Seixo rolado fluvial & 5,74 & 3,11 \\
\hline $\mathrm{a} / \mathrm{c}^{\mathrm{c}}$ & 0,784 & 0,508 \\
\hline \multicolumn{3}{|c|}{ Consumos $\left(\mathrm{kg} / \mathrm{m}^{3}\right)$} \\
\hline Cimento CPII-F 32 & 187 & 363 \\
\hline Areia & 649 & 687 \\
\hline Seixo rolado fluvial & 1074 & 1129 \\
\hline Água & 147 & 185 \\
\hline Aditivo & $1^{\mathrm{d}}$ & - \\
\hline Teor agregado miúdo (\%) & 37,7 & 37,8 \\
\hline Relação $1: \mathrm{m}^{\mathrm{e}}$ & $1: 9,21$ (ou 0,109$)$ & $1: 5($ ou 0,2$)$ \\
\hline Relação pedrisco/seixo rolado (\%) & $0 / 100$ & \\
\hline \multicolumn{3}{|c|}{ Massa unitária $\left(\mathrm{kg} / \mathrm{m}^{3}\right)$} \\
\hline Teórica & 2389 & 2387 \\
\hline Real & - & - \\
\hline
\end{tabular}





Figura 5. Transformadores da rede de distribuição com problemas de corrosão generalizada no tanque de óleo mineral e nas aletas de refrigeração. A seta está destacando ponto de vazamento de óleo do tanque

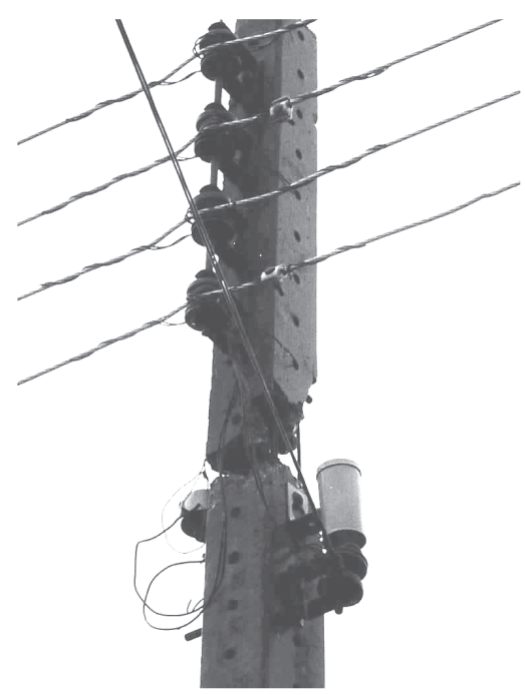

Figura 6. Poste, tipo duplo T, fraturado por esforços mecânicos superiores à resistência do concreto

dequadamente controlada, causando alta porosidade; ausência de espaçadores entre a ferragem e a fôrma, deixando a armadura parcialmente exposta à intempérie ou recoberta com pequena espessura de cobrimento; retração térmica superficial, conseqüiente da falta da cura úmida, nas primeiras idades da estrutura e, vazamento não-controlado da nata de cimento pela fôrma, entre outros problemas constatados e não discriminados. Estes são, em geral, os principais responsá-



Figura 7. Foto destacando a corrosão generalizada da armadura de um poste de concreto de seção circular, com desplacamento da sua cobertura concretada



Figura 8. Falhas de concretagem "bicheiras" em poste de concreto tipo duplo $T$

veis pela maior incidência de processos corrosivos na armadura metálica inserida no concreto, como mostrado na Figura 7.

A análise petrográfica dos agregados graúdos (seixos fluviais extraídos dos rios da região) revelou a presença, principalmente, de quartzo com extinção ondulante. Estes cristais podem, em presença dos álcalis (sódio e potássio) do cimento ou de outra fonte interna ou externa ao material, reagir e formar reações do tipo álcali-sílica ou álcali-silicato. A consequiência é o surgimento de um gel expansivo que absorve água e gera pressões internas e trincas no volume da estrutura, fragilizando o concreto e permitindo a penetração de íons agressivos à armadura. Este processo pode ocorrer a partir de poucos meses após exposição a estes agentes agressivos ${ }^{6,28,29}$. Um fator determinante para minimizar os produtos da reação é limitar a quantidade máxima de álcalis presentes, segundo a concentração de sódio equivalente $\left(\mathrm{Na}_{2} \mathrm{O}_{\text {eq }}=\mathrm{Na}_{2} \mathrm{O}+0,66 \mathrm{~K}_{2} \mathrm{O}\right)$ apresentada por Taylor ${ }^{9}$, em $4 \mathrm{~kg} / \mathrm{m}^{3}$. A análise química do cimento CPII-F 32, por AA, resultou em teor de sódio equivalente abaixo deste limite.

Por DRX, foram detectadas as fases químicas silicato hidratado de cálcio, carbonato de cálcio, portlandita, gipsita, sílica, entre outras fases em menores concentrações e não identificáveis pelo "ICDD". Com aumento do consumo do cimento, houve aparecimento da fase cristalina etringita, também verificada pela micrografia da superfície de fratura dos CP's correspondentes, tanto moldados em laboratório quanto obtidos em uma das fábricas de postes visitadas na zona industrial de Manaus, identificada nos picos de difração da Figura 9 (abreviada como E) e na Figura 10, pelos cristais aciculares visíveis no interior da fissura. 


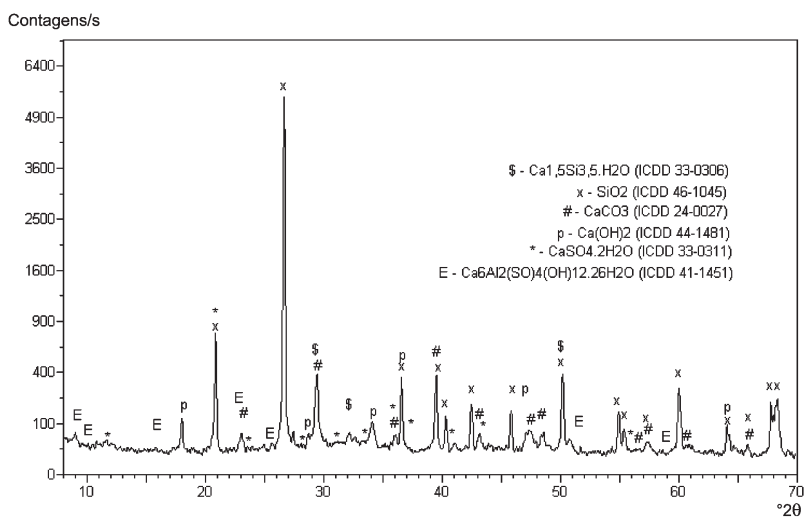

Figura 9. Difratograma de raios $X$ da argamassa de $C P$ de concreto com consumo de cimento de $363 \mathrm{~kg} / \mathrm{m}^{3}$

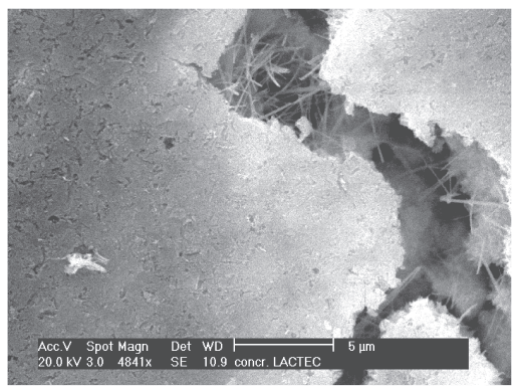

Figura 10. Micrografia, obtida por MEV, da superfície de fratura de CP de concreto com consumo de cimento de $363 \mathrm{~kg} / \mathrm{m}^{3}$

\section{Desempenho dos CP's de materiais metálicos pintados sob intemperismo artificial em câmara de névoa salina}

Dos sistemas analisados, pela dificuldade de se avaliar o processo de corrosão, uma vez que uns substratos apresentaram corrosão branca e outros, vermelha, procurou-se interpretar os resultados a partir da análise do alastramento da corrosão sob o corte, sendo o revestimento retirado com auxílio de removedor apropriado. Assim, avaliando-se os materiais, obtiveram-se as seguintes situações.

\section{Substrato à base de aço carbono 1010}

O melhor desempenho foi do sistema 1, CZAC, com fundo epóxi rico em zinco e acabamento poliuretano acrílico, por não apresentar bolhas e apenas poucos pontos de corrosão vermelha.

\section{Demais substratos (aço galvanizado, alumínio e galvalume)}

O melhor desempenho foi observado para os sistemas com poliuretano acrílico, códigos $\mathrm{ABAC}$, GBAC e ZBAC, cujos CP's não apresentaram bolhas ou manchas e demonstraram maior retenção de brilho e cor, comparativamente aos outros acabamentos.

Um "ranking" dos diversos sistemas de pintura e substratos utilizados foi estabelecido a partir da análise dos resultados nos sistemas de pintura com o corte, sendo GBAC e ABAC $>$ ZBAC $>$ CZAC $>>$ CFAC.

Observou-se que o sistema com acabamento poliuretano acrílico também foi o que apresentou melhor desempenho frente ao envelhecimento natural em ambiente salino, por cerca de 1 ano na atmosfera da região de Aracaju, estado de Sergipe ${ }^{3,12,13}$.

Nas Figuras 11 e 12 estão mostradas fotos de alguns dos CP's trabalhados, após exposição por 3500 h em névoa salina, com e sem o revestimento de pintura.

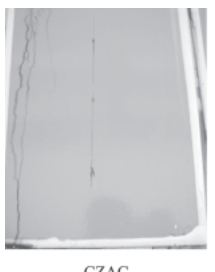

CZAC

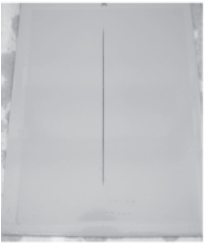

ABAC

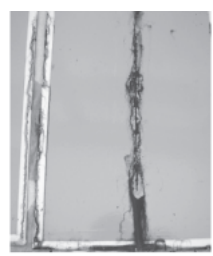

CFAC

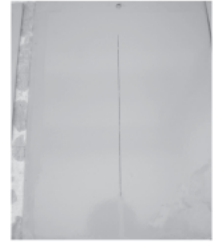

GBAC
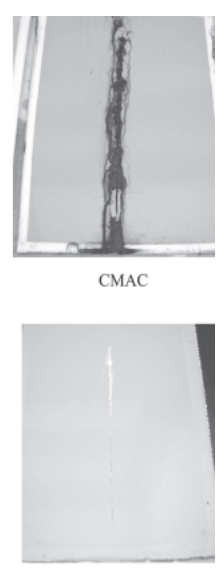

ZBAC
Figura 11. CP's metálicos pintados, após exposição por 3500 h em câmara de névoa salina

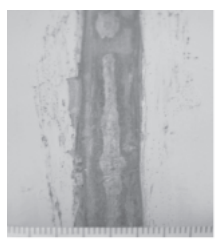

CZAC: $0 \mathrm{~mm}$

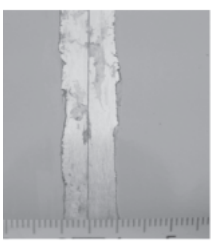

ABAC: até $1 \mathrm{~mm}$

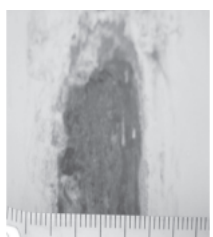

CFAC: $4-8 \mathrm{~mm}$



GBAC: até $0,5 \mathrm{~mm}$

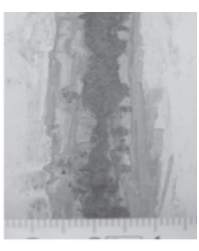

CMAC: $5-6 \mathrm{~mm}$

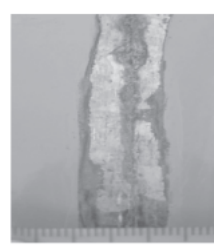

ZBAC: $3-4 \mathrm{~mm}$
Figura 12. CP's metálicos pintados, após exposição por 3500 h e remoção da camada de revestimento das tintas

\section{Desempenho dos CP's de materiais metálicos pintados sob intemperismo natural na cidade de Manaus}

No período de exposição ao ambiente natural de Manaus, nenhuma observação visual de problemas de corrosão nos CP's metálicos foi confirmada. Entretanto, algumas alterações nos sistemas de pintura, principalmente quanto ao brilho, foram observadas, conforme pode ser constatado na Figura 13. Neste caso, verificou-se que o desempenho dos CP's com acabamento à base de resina poliuretana acrílica resultou muito superior àqueles sistemas com acabamento alquídico ou poliuretano alifático, já que a diminuição das unidades de brilho não ultrapassou a $10 \%$ e, nestes últimos, o valor diminuiu, em média, $60 \%$.

Desempenho dos CP's de concreto sob intemperismo artificial em solução salina, com e sem aditivos anticorrosivos, pela medida do potencial de corrosão

Na Figura 14 encontram-se apresentados os resultados de potencial de corrosão $\left(\mathrm{E}_{\text {corr }}\right)$ dos CP's prismáticos de concreto armado, em função do tempo de exposição contínua ao intemperismo artificial em solução salina, IPC. Na Figura 15, os resultados de $\mathrm{E}_{\text {corr }}$ referem-se à exposição cíclica, $C I D$. Comparando-se os dois gráficos, observa-se que o teste $I P C$ resultou mais agressivo que o $C I D$, uma vez que, após 60 dias, alguns dos CP's de concreto com 


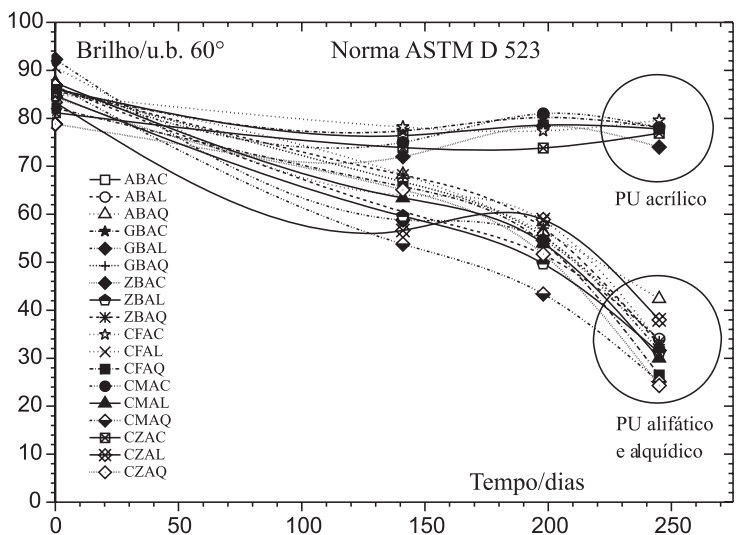

Figura 13. Curva ilustrando a variação percentual do brilho das tintas dos CP's metálicos instalados na ECA de Manaus, em função do tempo de exposição ao intemperismo natural

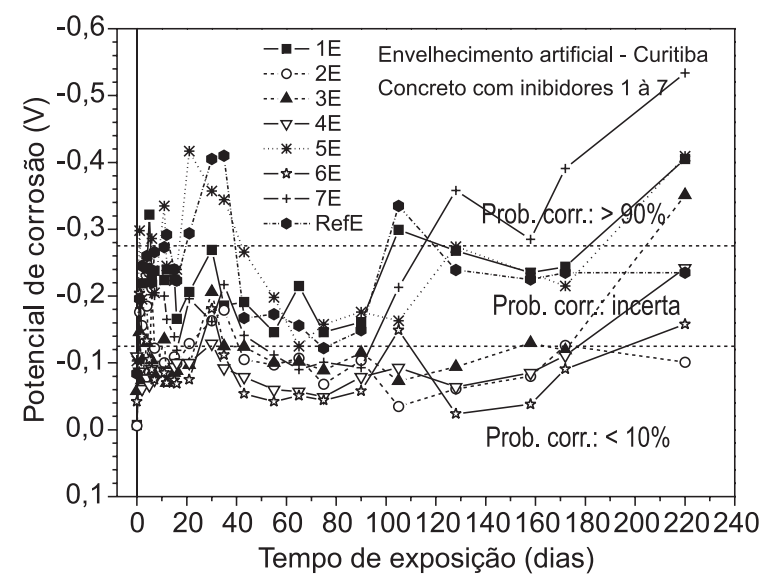

Figura 14. $E_{\text {corr }}$ versus tempo para os CP's, com e sem inibidores de corrosão, sob imersão parcial contínua, IPC, em solução salina

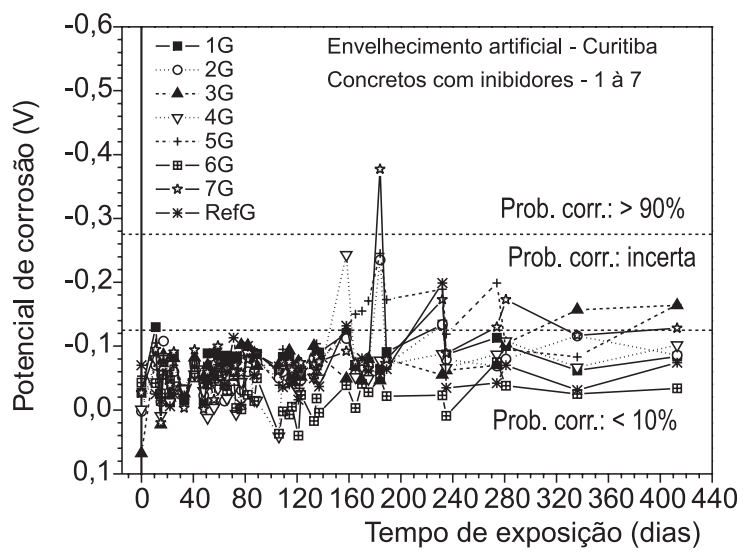

Figura 15. $E_{\text {corr }}$ versus tempo para os CP's com e sem inibidores em imersão cíclica, $C I D$

inibidores, tipos 1, 3, 5 e 7, conforme Tabela 3, além do CP sem inibidor, começaram a apresentar valores de $\mathrm{E}_{\text {corr }}$ na região com $50 \%$ de probabilidade de corrosão e, após 350 dias, já se encontravam na região com corrosão ativa (potenciais mais negativos que $-0,275$ V). No entanto, os CP's com inibidores tipo 5 e 7 , submetidos ao $C I D$, somente após 150 dias começaram a mostrar sinais de ativi- dade corrosiva, sendo que os restantes ainda permaneceram na região de baixo risco de corrosão (potenciais menos negativos que $0,125 \mathrm{~V})$. Avalia-se desta forma que os resultados obtidos corroboraram o enunciado na literatura ${ }^{6}$, ou seja, de que há um efeito facilitador do processo de corrosão em estruturas de concreto armado parcialmente submersas, principalmente, quando submetidas a soluções salinas, tal como o elaborado no ciclo IPC (com ciclos de molhagem e secagem).

Verificou-se também comparativamente ao CP sem inibidor, que alguns concretos contendo este tipo de aditivo aceleraram a corrosão nos dois tipos de testes realizados. Este comportamento deixa dúvidas quanto à sua viabilidade de uso em quaisquer ambientes sem prévio conhecimento dos mecanismos de degradação envolvidos. É importante salientar, neste caso, que a análise química por CI da solução com aditivo ${ }^{27}$ indicou que alguns inibidores comerciais avaliados apresentaram teores iônicos que podem ser prejudiciais à estrutura de concreto, tais como nos casos dos inibidores 4,5 e 6, com teores de $\mathrm{NO}_{3}$ - da ordem de 6 a $15 \mathrm{~g} / \mathrm{L}$; o inibidor 4, com 2,2 $\mathrm{g} / \mathrm{L}$ de $\mathrm{Na}^{+}$e $0,4 \mathrm{~g} / \mathrm{L}$ de $\mathrm{K}^{+}$; e o inibidor 3, com $7 \mathrm{~g} / \mathrm{L}_{\text {de }} \mathrm{Mg}^{2+}$. Estes íons presentes nas concentrações indicadas, e dependendo da sua composição química, podem ter sido causadores da degradação do concreto, por dissolução química dos constituintes do cimento, reações de troca iônica e formação de géis expansivos ${ }^{28,29}$.

Na Figura 16,estão mostradas curvas de potencial de corrosão da armadura de 2 CP's de concreto fabricados por um dos fornecedores de artefatos de concreto para a RDE de Manaus e com traço otimizado e fabricado em laboratório, conforme listado na Tabela 4. Ambos encontram-se expostos na ECA de Manaus. Os valores médios apresentados no período de medida indicaram que o aço se encontra na região de passividade, não havendo tendência à corrosão, sendo coerente com o comportamento observado na Figura 14, onde, em ambiente de maior agressividade, o concreto-referência somente apresentou alteração do potencial de corrosão após 100 dias de exposição à solução salina, bem mais agressiva. Também, deve-se ressaltar que o tempo de exposição não foi grande o suficiente para se fazer qualquer correlação entre o envelhecimento artificial e o natural.

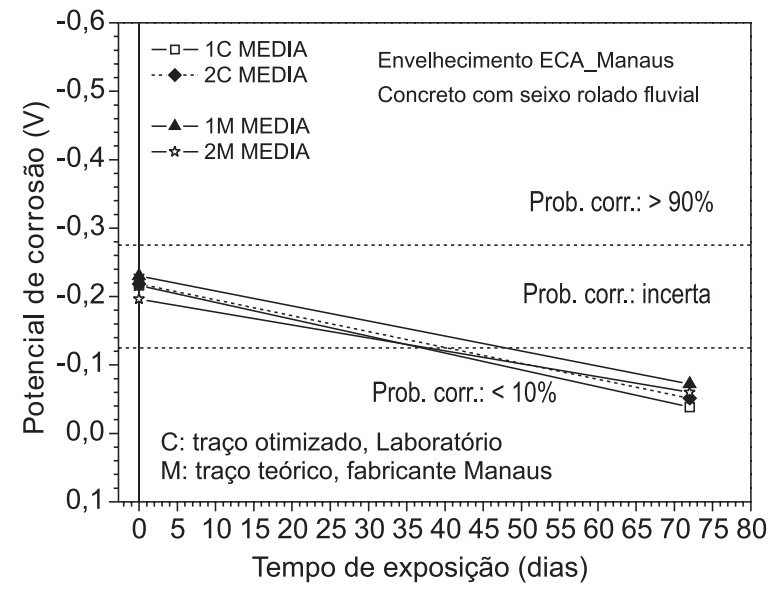

Figura 16. $E_{\text {corr }}$ versus tempo para os CP's fabricados com traço e concreto de fabricante local e traço otimizado, em laboratório.

Tal como apresentado na literatura ${ }^{30,31}$, os traços de concreto com seixo rolado analisados apresentaram fratura preferencial na interface pasta de cimento-agregado (também conhecida como zona de transição), conforme apresentado na Figura 17a, pelo registro fotográfico da superfície de fratura do CP, e na Figura 17b, pela micrografia apresentada por MEV, onde se identifica o descolamento 
na interface pasta de cimento-agregado (indicado pela seta) e pouca argamassa aderida à superfície do agregado. Foi verificada, também, a necessidade de se controlar os parâmetros de dosagem, principalmente a temperatura de fabricação do concreto, por causa da obtenção de diversos CP's com porosidade elevada e alta friabilidade. A falta deste controle pode, também, ser um dos fatores determinantes para a baixa durabilidade frente a alguns ambientes agressivos e para a limitada resistência do concreto, como demonstrado nas Figuras 6 e 7.
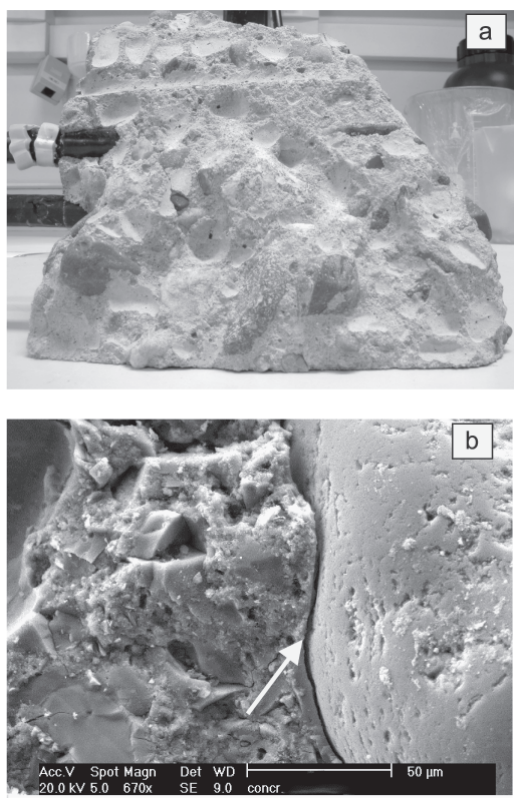

Figura 17. Foto da superfície de fratura do CP de concreto com traço contendo agregado graúdo tipo seixo rolado (a); micrografia da superfície de fratura do CP na região de interface pasta de cimento-agregado (b)

Estudos da literatura com agregados locais ${ }^{32}$, indicam resistências à compressão do concreto, dependentes da distribuição granulométrica dos seixos, com valores publicados dentro de uma faixa considerada por Mehta e Monteiro ${ }^{7}$ como de resistências moderadas (entre 20 e $40 \mathrm{MPa}$ ). Em estudos para concreto de alta resistência, Pinho et al. ${ }^{33}$ e Souza et al. ${ }^{31}$ encontraram como fator limitante o agregado graúdo, cujas superfícies de fratura demonstraram ser intragranulares.

Traços com consumos maiores de cimento $/ \mathrm{m}^{3}$ resultaram em CP's com maior concentração e dispersão pela argamassa de grandes cristais de portlandita, como demonstrado na micrografia e espectro obtidos por MEV e EDS das Figuras 18a e b, respectivamente. Pelo limite de detecção da técnica, não foi possível verificar a presença do oxigênio.

Segundo Agostini et $a l .^{34}$, o aumento no consumo de cimento pode chegar a proporcionar heterogeneidades inerentes à pasta, onde a presença de grandes cristais de portlandita representa outro fator limitante de fratura pela clivagem sob tensão, uma vez que passam a se comportar como áreas vulneráveis à microfissuração.

\section{CONCLUSÕES}

\section{Sistemas de pintura}

Para os sistemas de pintura aplicados sobre os diversos substratos metálicos expostos em ambiente artificial sob névoa salina, constatou-se que para o substrato à base de aço carbono 1010, o melhor
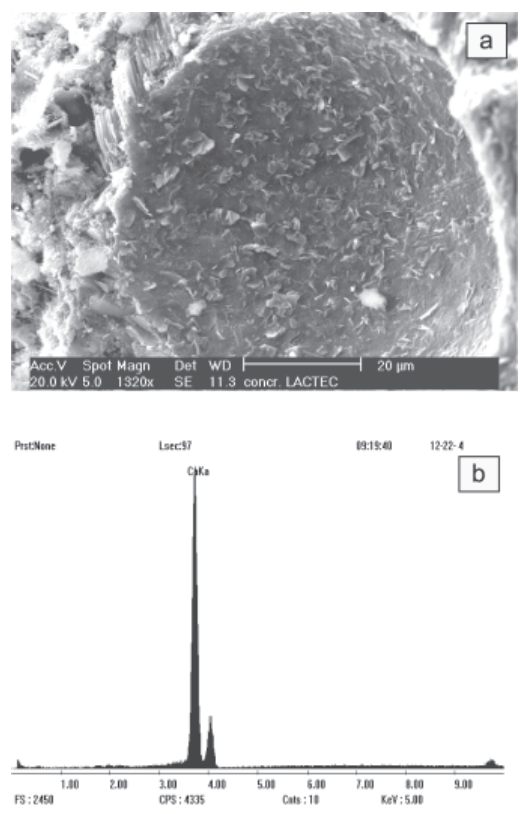

Figura 18. Foto da superfície de fratura do CP de concreto com traço contendo consumo de cimento mais elevado, em torno de $360 \mathrm{~kg} / \mathrm{m}^{3}$ (a); espectro por EDS da região analisada $(b)$

desempenho foi o do sistema CZAC, com fundo epóxi rico em zinco e acabamento poliuretano acrílico e, para os outros substratos (aço galvanizado, alumínio e galvalume), o melhor desempenho foi observado para os sistemas com poliuretano acrílico, códigos ABAC, GBAC e ZBAC.

Assim, a partir da análise dos resultados, foi estabelecido um "ranking" do melhor ao pior desempenho dos sistemas de pintura e substratos utilizados, sendo, respectivamente, GBAC e ABAC > $\mathrm{ZBAC}>\mathrm{CZAC}>>\mathrm{CFAC}$.

Quanto aos CP's metálicos sujeitos ao envelhecimento em ambiente natural na ECA de Manaus, observou-se nenhuma evidência visual de problemas de corrosão na superfície dos CP's, fato atribuído ao pouco tempo de exposição ao intemperismo natural e, alterações nos sistemas de pintura, principalmente, quanto ao brilho, sendo que o desempenho dos CP's com acabamento à base de resina poliuretana acrílica resultou muito superior (com diminuição nas unidades de brilho < 10\%) àqueles sistemas com acabamento alquídico ou poliuretano alifático (os valores resultantes diminuiram, em média, 60\%).

Recomenda-se, desta maneira, muita cautela na escolha do sistema de pintura a ser adotado, principalmente, se é desejado alto desempenho de cobertura.

\section{Estruturas de concreto}

A análise das estruturas de concreto (postes e cruzetas), instaladas na RDE da região de Manaus, indicou problemas gerados no processo de fabricação quanto a consumo de cimento, espessura de cobrimento da camada concretada sobre a armadura, resistência máxima dependente do seixo rolado fluvial e possibilidade de reações do tipo álcali-silicato.

Quanto aos concretos, com e sem aditivos anticorrosivos, submetidos ao intemperismo artificial em solução salina, foi verificado que alguns dos CP's com inibidores - tipos 1, 3, 5 e 7 - além do CP sem inibidor, começaram a apresentar valores de potencial de corrosão na região com $50 \%$ de probabilidade de corrosão após 60 dias de exposição ao ciclo de envelhecimento contínuo (IPC), passando para 
a região de corrosão ativa após 350 dias. No entanto, considerando o ciclo de imersão descontínua, $C I D$, os CP's com inibidores tipos 5 e 7 apresentaram alterações no $\mathrm{E}_{\text {corr }}$ somente após 150 dias mas, mesmo assim, com os potenciais permanecendo na região de baixo risco de corrosão.

Sob envelhecimento natural na ECA de Manaus, e com agregados locais, nenhuma evidência de corrosão foi detectada no período de um ano de análise.

\section{AGRADECIMENTOS}

Ao Instituto de Tecnologia para o Desenvolvimento, à Manaus Energia, ao Programa de Pós-Graduação em Engenharia de Materiais e Processos da Universidade Federal do Paraná e à Agência Nacional de Energia Elétrica (ANEEL), pela infra-estrutura e apoio financeiro para execução deste projeto de pesquisa.

\section{REFERÊNCIAS}

1. http://www.abraco.org.br/InibidorVolatildeCorrosaoORVIC.pdf, acessada em Janeiro 2005.

2. Leal, T. F. M.; Fontenele, A. P. G.; Pedrotti, J. J. Fornaro, A.; Quim. Nova 2004, 27, 865 .

3. Garcia, C. M.; Portella, K. F.; Vergés, G. R.; Freire, K. R. R.; Joukoski, A.; Baron, O.; Motta, H. N.; Paula, J. F.; Relatório 4082/2003, LACTEC: Curitiba, 2003.

4. Henke, S. L.; Kenny, E. D.; Comunicação Técnica 0011/1990, COPEL/ LAC: Curitiba, 1990.

5. Gnecco, C.; A pintura na proteção anticorrosiva. Apostila nível técnico. Sherwin-Williams do Brasil - Divisão Sumaré: Sumaré, SP, 1998.

6. Neville, A. M.; Giammusso, S. E., trads.; Propriedades do concreto, $2^{\mathrm{a}}$ ed., PINI Ltda:: São Paulo, 1997.

7. Mehta, P. K.; Monteiro, P. J. M.; Concreto: estruturas, propriedades e materiais, PINI Ltda: São Paulo, 1994.

8. Associação Brasileira de Normas Técnicas; NBR 12655, ABNT: Rio de Janeiro, 1996.

9. Taylor, H. F. W.; Cement chemistry, Academic Press: New York, 1990.

10. Associação Brasileira de Normas Técnicas; NBR 6209, ABNT: Rio de Janeiro, RJ, 1986.

11. Associação Brasileira de Normas Técnicas; NBR 7011, ABNT: Rio de Janeiro, 1981
12. Portella, K. F.; Garcia, C. M.; Corrêa, A. P.; Joukoski, A.; Relatório Técnico 0811/2005, LACTEC/MANAUS ENERGIA/ANEEL: Curitiba, 2005.

13. Vergés, G. R.; Dissertação de Mestrado, Universidade Federal do Paraná, Brasil, 2005.

14. American Association for Testing and Materials; $B$ 117-03, ASTM: West Conshohocken, 2003.

15. American Association for Testing and Materials; D 2244-02 e 1, ASTM: Philadelphia, 2002.

16. American Association for Testing and Materials; D 714-02, ASTM: West Conshohocken, 2002.

17. American Association for Testing and Materials; D 610-01, ASTM: West Conshohocken, 2001

18. American Association for Testing and Materials; D 659-86, ASTM: West Conshohocken, 1986 (withdrawn 1989).

19. American Association for Testing and Materials; $D$ 772-86, ASTM: West Conshohocken, 2000.

20. American Association for Testing and Materials; D 3359-02, ASTM: West Conshohocken, 2002.

21. American Association for Testing and Materials; D 660-93, ASTM: West Conshohocken, 2000

22. American Association for Testing and Materials; D 661-93, ASTM: West Conshohocken, 2000.

23. Associação Brasileira de Normas Técnicas; NBR 9778, ABNT: Rio de Janeiro, 1987.

24. Associação Brasileira de Normas Técnicas; NBR 5738. ABNT: Rio de Janeiro, 2003

25. Associação Brasileira de Normas Técnicas; NBR 7223. ABNT: Rio de Janeiro, 1992

26. Guimarães, S. B.; Relatório Técnico, UFPR/LAMIR: Curitiba, 2004.

27. Freire, K. R. R.; Dissertação de Mestrado, Universidade Federal do Paraná, Brasil, 2005.

28. Biczok, I.; Corrosión y protección del hormigón. Urmo S. A. de Ediciones: España, 1968.

29. Scrivener, K. L.; Young, J. F., eds.; Mechanisms of chemical degradation of cement-based systems, $1^{\text {st }}$ ed., E\&FN Spoon: London, 1997.

30. Silva, M. A.; Rocha, F. S.; Anais do $44^{\circ}$ Congresso Brasileiro do Concreto, Belo Horizonte, Brasil, 2002.

31. Souza, P. S. L.; Dal Molin, D. C. C.; Anais do $43^{\circ}$ Congresso Brasileiro do Concreto, Foz do Iguaçu, Brasil, 2001.

32. Said, M.; Rocha, F. S.; Ferreira, J. B.; Anais do $46^{\circ}$ Congresso Brasileiro do Concreto, Florianópolis, Brasil, 2004.

33. Pinho, J. R. S.; Dias Júnior, U. S.; Pompeu Neto, B. B.; Barata, M. S.; Anais do $46^{\circ}$ Congresso Brasileiro do Concreto, Florianópolis, Brasil, 2004.

34. Agostini, L. R. S.; Longati, E.; Anais do $44^{\circ}$ Congresso Brasileiro do Concreto, Belo Horizonte, Brasil, 2002. 